\section{A rare case of nasal schwannoma of middle turbinate}

\author{
Nilam U. Sathe, Sheetal Shelke, \\ Hetal Marfatia, Shampa Mishra \\ Department of Ear, Nose and Throat, \\ King Edward Memorial Hospital and Seth \\ G.S. Medical College, Mumbai, India
}

\section{Abstract}

Schwannoma is a benign, slow-growing nerve sheath tumor derived from the Schwann cells. Cases with nasal schwannoma arising from nasal septum and inferior turbinate have been reported, though being rare. A 32-yearold male patient presented to our hospital with left side progressive nasal blockage since 4 months and multiple episodes of epistaxis. Anterior rhinoscopy revealed left side smooth spherical nasal mass, which was bleeding on touch. Computed tomography was done, which was suggestive of right side deviated nasal septum. Left nasal cavity soft tissue lesion extended into anterior ethemoid cells, causing widening of the osteomeatal complex. The patient underwent endoscopic excision of nasal mass. Histopathology of nasal mass suggested nasal schwannoma. Though nasal schwannoma is rare, it should be considered as a differential diagnosis in case of unilateral nasal mass with epistaxis. Definitive diagnosis of schwannoma can be considered only after final histopathological reporting of the surgical specimen.

\section{Introduction}

Schwannoma is a benign, slow-growing nerve sheath tumor derived from the Schwann cells. Approximately $25-45 \%$ of schwannomas occur in the head and neck and only about $4 \%$ of these last arise in the sinonasal tract. ${ }^{1}$ Within the sinonasal tract, the ethmoidal sinus is the most commonly involved site, followed by the maxillary sinus, nasal fossa, and sphenoid sinus. Frontal sinus involvement is extremely rare, and has been reported in very few cases. ${ }^{2}$ Cases with nasal schwannoma arising from nasal septum and inferior turbinate have been reported. ${ }^{3,4} \mathrm{Nasal}$ schwannoma has no age or sex predilection.

\section{Case Report}

A 32-year-old male patient presented with left side progressive nasal blockage since 4 months and multiple episodes of epistaxis. The patient had one episode of severe epistaxis, which was managed by nasal packing in another hospital. He had history of rhinorrhea since 4 months. Anterior rhinoscopy revealed left side smooth spherical nasal mass, which was bleeding on touch. Posterior rhinoscopy was normal.

Computed tomography (CT) was done and it was suggestive of right side deviated nasal septum. Left nasal cavity $3 \times 2 \mathrm{~cm}$ soft tissue lesion, which extend into anterior ethemoid cells and causing widening of osteomeatal complex (Figure 1). Superiorly lesion was extending up to cribriform plate and inferiorly turbinate. It also showed involvement of frontal and maxillary sinus. Magnetic resonance imaging (MRI) was done to know the soft tissue details of the lesion. Lesion was hypointense on T1 weighted MRI, showed moderate homogenous post contrast enhancement (Figure 2). T2 Weighted MRI showed heterogeneously hyperintense lesion with central hypointense area. Lesion was limited to nasal cavity and anterior ethmoid cells. Secondary sinusitis was seen in frontal and maxillary sinus. These radiological features were suggestive of inverted papilloma or a neurogenic tumor.

Patient underwent endoscopic excision of nasal mass. Mass was arising from middle turbinate and occupying middle meatus. Mass excision was done with trimming of middle turbinate (Figure 3). Maxillary and frontal osteum widened and mucoid secretions drained.

Histopathology of nasal mass showed hypercellularity with prominent Antony A area, which was suggestive of nasal schwannoma (Figure 4). On immunohistochemistry, cells were diffusely positive for S100.

The patient followed up for 4 months. He has then recovered without any symptoms or signs of recurrence.

\section{Discussion}

Schwannoma is a slow-growing, solitary, benign tumor. It is also known as neurilemmoma. Schwannomas are more commonly seen in deep soft tissue intracranially. It is rarely seen in sinonasal tract. A sinonasal schwan-
Correspondence: Nilam U. Sathe, Department of Ear, Nose and Throat, King Edward Memorial Hospital and Seth G.S. Medical College, Patidar Complex 304/ B, Mumbai 400083, India. Tel: +91.02225782801 - Fax: +91.9821309298.

E-mail:drneelam_s@yahoo.co.in

Key words: Nasal schwannoma; Middle turbinate; Tumor.

Conflict of interest: the authors declare no potential conflict of interest.

Received for publication: 12 February 2016.

Revision received: 20 May 2016.

Accepted for publication: 23 May 2016.

This work is licensed under a Creative Commons Attribution NonCommercial 4.0 License (CC BYNC 4.0).

(C) Copyright N.U. Sathe et al., 2016 Licensee PAGEPress, Italy

Surgical Techniques Development 2016; 6:6467 doi:10.4081/std.2016.6467

noma can be found at different sites, including the nasal septum, tip of the nose, turbinate, paranasal sinus and nasopharynx..$^{3-}$

5 Ethmoidal sinus is most common site amongst sinuses. Nasal schwannomas are presumed to be arising from the sheath of the ophthalmic and maxillary branches of the trigeminal nerve and autonomic ganglia. ${ }^{3}$ Neoplasm can be sporadic or associated with neurofibromatosis 2. Nasal masses have variable differential diagnosis like nasal polyp, rhinosporidiosis, rhinoscleroma, nasal tuberculosis, angiofibroma, neurifibroma, inverted papilloma, meningioma, nasal glioma, encephalocele rarely neurilemmoma. The possibility of these tumors needs to be ruled out although specific diagnosis from imaging study is difficult.

Schwannoma patients usually present with progressive unilateral nasal blockage. Most of the schwanomas causes epistaxis and rhinorrhea. Few patients also give history of anosmia and headache. Some cases with intracranial extension have also been reported in literature. ${ }^{1}$ Sphenoid sinus schwannomas may present with nerve palsies leading to diplopia and blurring of vision. ${ }^{6}$

CT shows size, extend of lesion and surrounding bone erosion. Bony details are useful in endoscopic surgery as surgical landmarks. But soft tissue is well demarcates in MRI. In presented case CT scan shows soft tissue involvement of maxillary sinus (Figure 1) 
and frontal sinus but MRI scan (Figure 2) clearly differentiate between tumor and fluid collection in sinuses secondary to mass in nasal cavity. MRI is also useful in cases with intracranial extension. ${ }^{3}$ On MRI, schwannomas may typically appear isointense in T1weighted sequences and hyperintense in T2weighted sequences. These radiological features may be variable in few cases so need correlation with clinical and histopathological features. ${ }^{2,6}$

Macroscopically theses tumors are well circumscribed, encapsulated may be gray, white or pink in color. Microscopically, tumor cells are spindled schwann cells with indistinct cytoplasmic borders. These cells are arranged in interlacing fascicles. The hyper cellular areas are called Antoni A, which contain rows or palisades of nuclei aligned around eosinophilic processes called Verocay bodies. Hypocellular areas are called Antoni B, which contain oval to spindle cells arranged more haphazardly in a loose fibrous matrix. ${ }^{4}$ Thickened hyalinized vessels are prominent in many cases. Tumors cells are diffusely immunopositive for S100 protein and collagen type IV with delicate pericellular reactivity reflecting basement membrane like deposition (Figure 4).

Schwannomas of sinonasal tract can be easily approached with endoscope. It has advantage of early recovery and it avoids external scar. Few cases with extensive lesion may require external approach. Neurosurgeons assistance is required in cases with extensive intracranial extension.

\section{Conclusions}

Although nasal schwannoma is rare, it should be considered as differential diagnosis in case of unilateral nasal mass with epistaxis. MRI should be considered in patients with nasal mass to know the exact extent of the lesion and to rule out different soft tissue lesions. Definitive diagnosis of schwannoma can be considered only after final histopathological reporting of the surgical specimen.

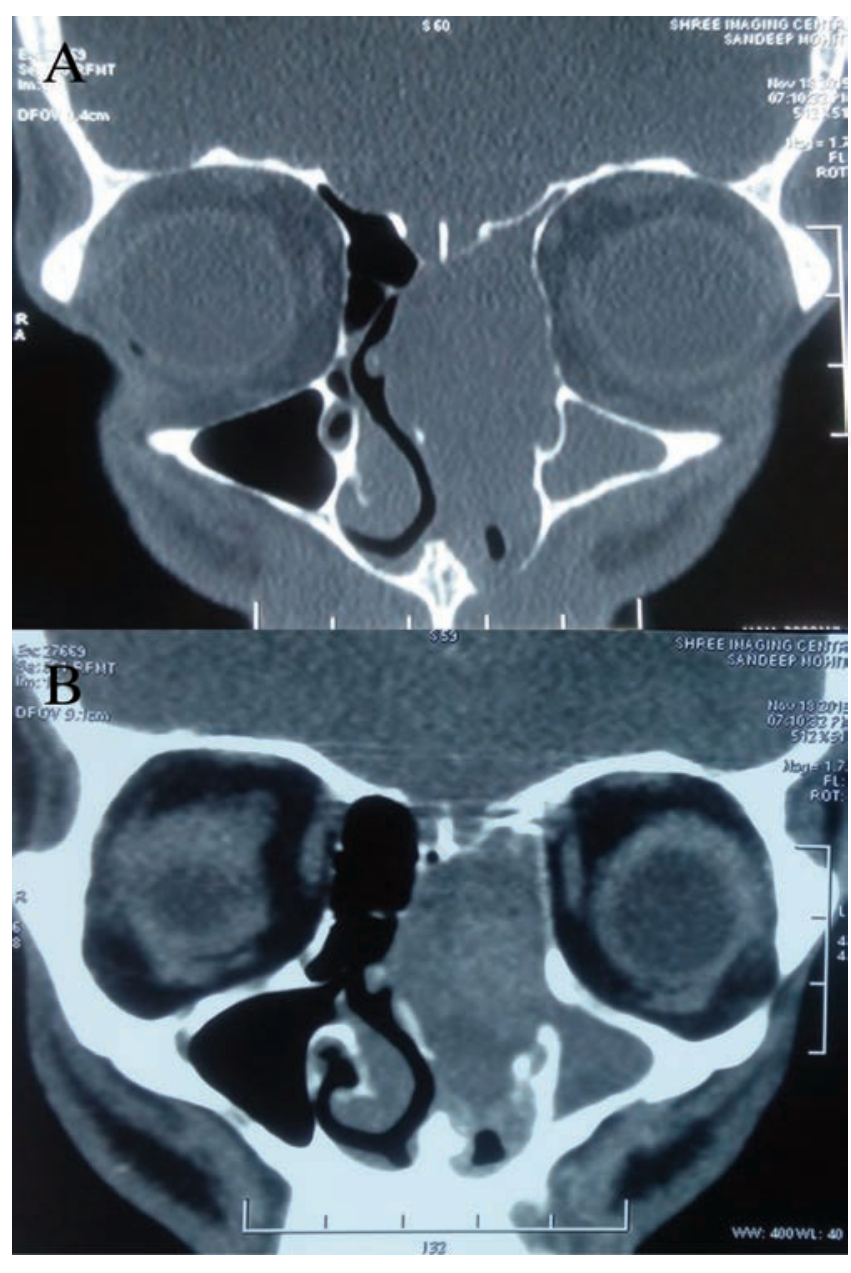

Figure 1. Computed tomography of paranasal sinus sagittal section. A) Left side nasal cavity showing the soft tissue lesion involving middle turbinate with thinning of medial lamina and deviation of septum towards the right side. B) Soft tissue window showing widening of osteomeatal complex with involvement of maxillary sinus.

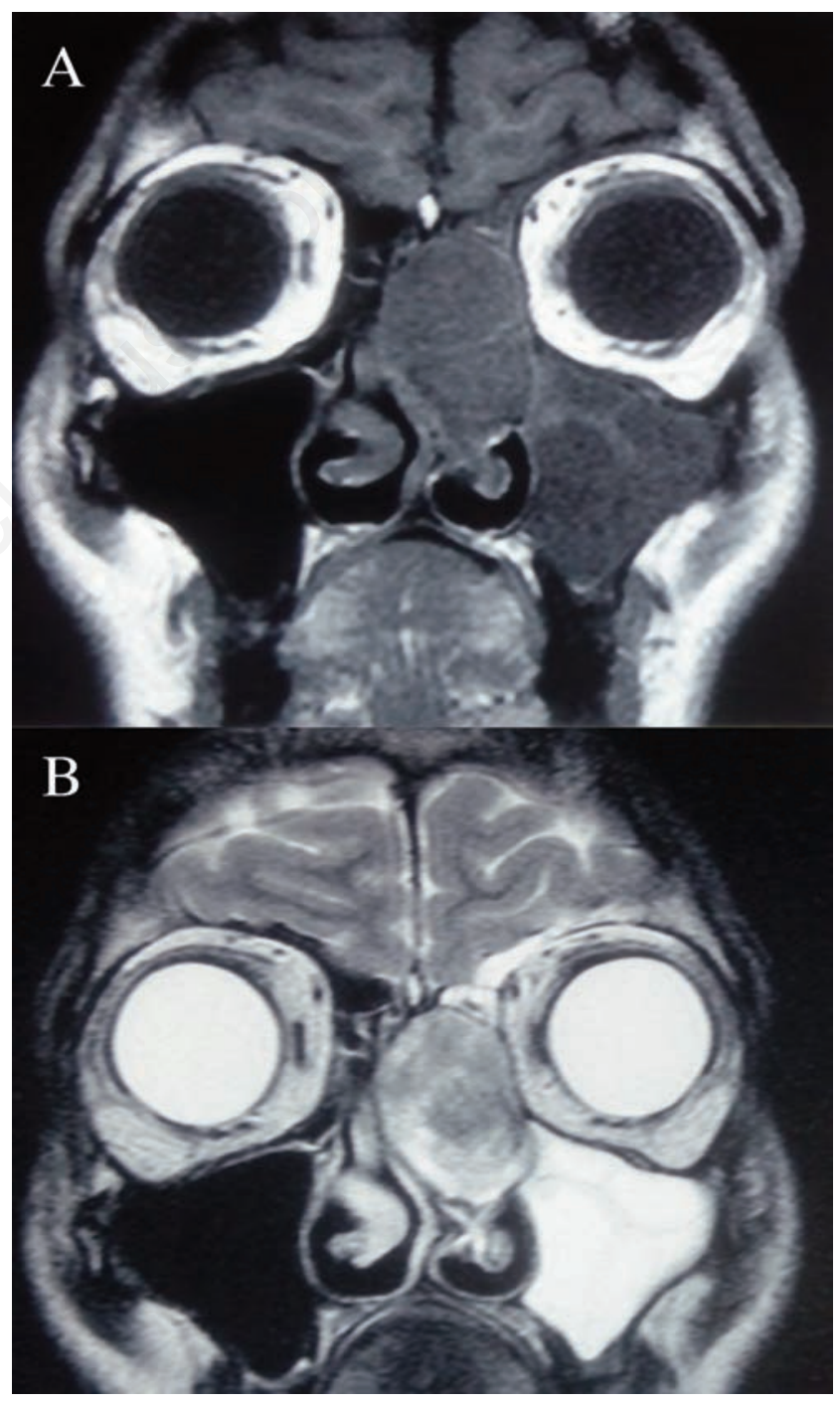

Figure 2. Magnetic resonance imaging representing the sagittal section of paranasal sinus: A) T1 weighted image showing hypointense lesion of nasal cavity; B) well defined heterogeneous hyper-intense soft tissue lesion in osteomeatal complex causing obstruction of drainage of frontal and maxillary sinus with secondary sinusitis. 


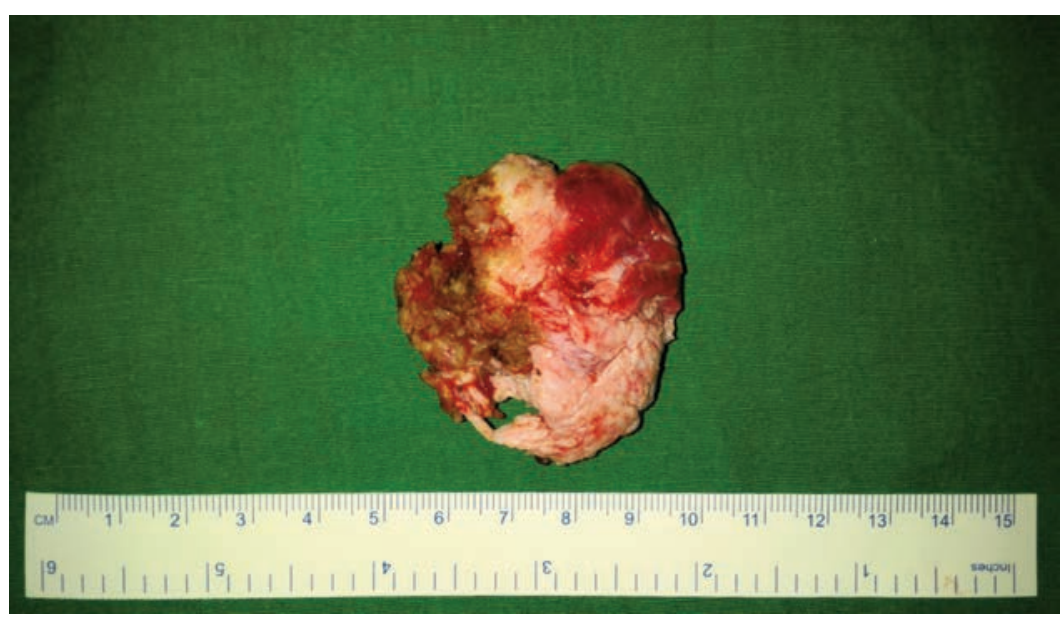

Figure 3. Nasal mass after endoscopic excision.

\section{References}

1. Takahashi EA, Hull NC, Stevens CJ, et al. Sinonasal schwannoma: a case report and updated review of the literature. Open $\mathrm{J}$ Med Imag 2015;5:66-70.

2. Mangubat EZ, Pitelka L, Petruzzelli GJ, Byrne RW. Frontal sinus schwannoma: case report and review of literature. Skull Base Rep 2011;1:17-22.

3. Mitra B, Debnath S, Paul B, et al.
Schwannoma of nasal septum: a rare case report with literature review. Egypt $\mathrm{J}$ Ear Nose Throat All Sci 2012;13:121-5.

4. Khodaei I, Davies E. Schwannoma of the inferior turbinate: case report and review of literature. Radiol Bras 2008;41:205-6.

5. Leakos M, Brown DH. Schwannomas of the nasal cavity. J Otolaryngol 1993;22:1067.

6. Cheng YC, Sun PL, Chen HJ, et al. Benign schwannoma in the sphenoid sinus: two case reports. Chin J Radiol 2010;35:179-83.

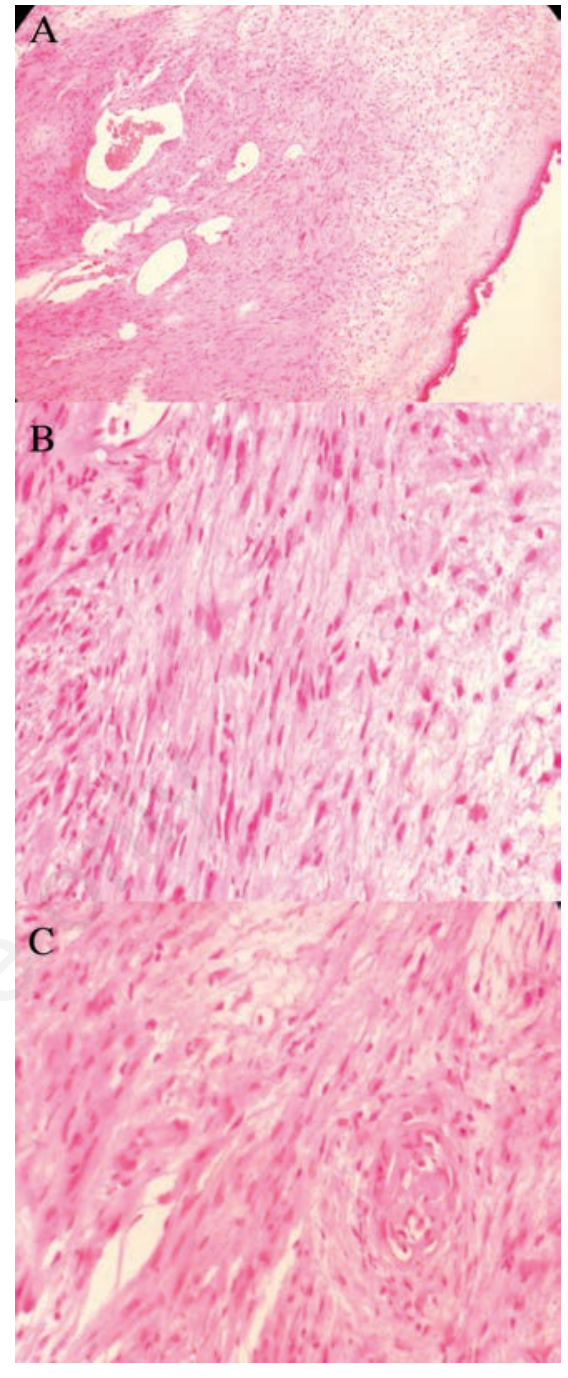

Figure 4. Histopathological examination typical of schwannoma (Antoni types A and $B$ tissue). 